\title{
ON ANIMALS AND PAIN
}

\author{
ANN SQUIRE \\ ANN SQUIRE
American society for the Prevention \\ of Cruelty to Animals
}

Do animals feel pain? This question, simple on its face, is one which has engendered controversy for many years and which continues to do so today. The way that each of us answers this question is important, because it lays the foundation for our attitudes toward and treatment of members of other species.

One of the first modern philosophers to address the issue was Descartes, who responded in the negative. Animals, Descartes said, were simply automata which moved in reaction to external and internal stimuli but did not sense pain or pleasure.[1] Accordingly, there was little reason to be concerned about the way they were treated. Many modern scientists continue to look upon the issue of animal sensitivity as an open question, citing a lack of "proof" that animals can experience feelings similar to our own. However, there is an overwhelming body of evidence-physiological, behavioral, and evolutionary-which points to the conclusion that animals, like humans, do feel and respond to painful stimulation.

First, there are strong physiological similarities between the nervous systems of humans and "higher" animals. A rat, for example, has receptors and sensory nerves that respond to heat, cold, pressure, and other stimuli in much the same way as do human sensory systems. The brain structures that mediate pain perception are equally well developed in humans and many other animals and birds. This similarity of structure and function suggests that what produces pain in a human animal should also produce pain in an animal. Indeed, this similarity is routinely presented as justification for using animals in experiments designed to predict something about human systems and behavior.

Behavioral evidence also indicates that animals feel pain. Behavior displayed in response to noxious stimulation is remarkably consistent across species. The reaction to

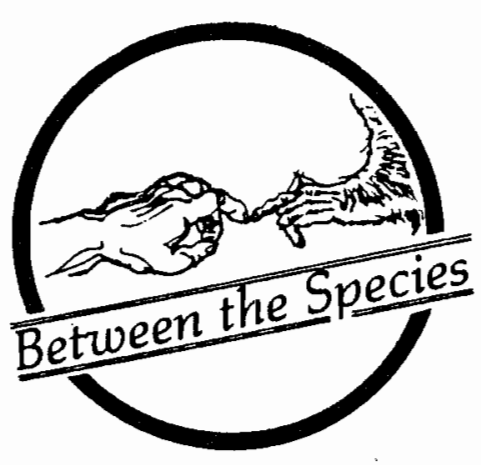

extreme pressure on a limb, for instance, almost universally consists of a cry and withdrawal of the affected part. A man who hits his thumb with a hammer, a cat whose foot is stepped on, and a mouse whose tail is pinched show identical response. This similarity of behavior should tell us that animals feel and respond to pain in the same way that humans do.

Pain also serves as an important signal that something is wrong. By avoiding painful stimuli, we minimize the risk of injury and enhance the chances that we as individuals, as well as our species, will survive. It is safe to conclude that an animal without the capacity to feel and respond to pain would not survive for very long.

Given this evidence, can there be any doubt that animals sense pain? Clearly, the answer is no. But we are not out of the woods yet. For while most people will agree that animals feel pain, not everyone will concede that they suffer from or are "bothered by" painful stimulation. The distinction here is between sensation and perception. While animals may sense pain, many people argue that they do not perceive it. This apparent independence of sensation and perception has allowed otherwise sensitive people to subject animals to extreme cruelties with the justification that "they don't feel it." The most common rationale for this attitude is the notion that perception requires thought--that if an animal cannot reflect on its pain, then it cannot suffer. This argument contains two major fallacies.

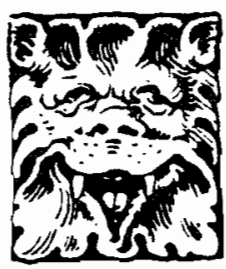

COMMENT 
First, there is no conclusive evidence that animals are incapable of thought. A recent story in The National Geographic described the relationship between Koko, a gorilla, and a kitten she had "adopted." The grief that koko showed after the kitten's death suggests not only the capacity to think about a vague concept, i.e.., death, but also the capacity to experience psychological pain.

Second, there is no evidence that it is necessary to think in order to suffer. To be sure, the human capacity for thought gives human suffering an added dimension--anticipation of the painful event, remembering it afterward, and so on. But this does not mean that humans suffer any more acutely. Indeed, one can inagine a situation in which an animal would suffer more than a human precisely because of the animal's limited understanding of the situation. A visit to the veterinarian or physician provides a good illustration of this point. An animal, not comprehending what is going on, frequently responds with fear and anxiety to the strange surroundings and unexpected procedures at the veterinarian's office. In the analogous situation, a human's fears can be allayed by an understanding of the procedures to be performed and the knowledge that the experience will ultimately benefit the patient's health. It can be argued that the animal, because it lacks understanding of the situation, actually suffers more than the human. [2]

The fact that animals cannot communicate with us verbally has reinforced the notion that they cannot think and, therefore, do not experience pain. In a 1984 Congressional hearing on the steel jaw leghold trap, one trapping advocate stated that he would not believe that a trapped animal was in pain until the animal told him so in our own language!

But, as we have seen, the capacity to sense pain is basic and is unrelated to language. We do not doubt that human infants feel pain even before they have learned to talk; so, why should the fact that animals cannot talk lead us to doubt that they feel pain ? There can be no justification for applying one set of criteria to humans and a different set to animals.

All the evidence indicates that animals are more sirailar to humans than we have ever suspected. If they are like us, are we justified in doing things to animals that we would not do to other humans? Or do we have an obligation to treat animals the way we would wish to be treated? Luckily, more and more people are recognizing the similarity between animals and humans and are demanding that animals be treated with the consideration and respect that theix sentient natures require.

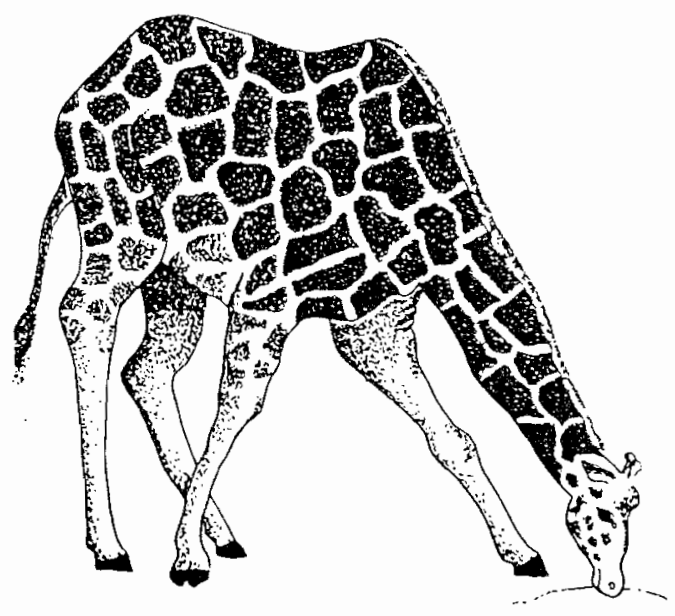

Notes

1. See Descartes' Discourse on Method, Chapter 5, and his letter to Henry More, of 1649.

2. Bernard Rollin also discusses this possibility in Animal Rights and Human Morality (Buffalo: Prometheus Books, 1981), p. 33.

Woe, that I should ever be a tropical fish Whose life is spent in an aquarium Trapped in what could hardly be called a world And destined to wait patiently for food.

How infinitely better that I should know freedom And take ny chances amidst truer surroundings Which, though alive with danger and uncertainty Abound with variety and passicn, as well.

\section{Mark Clayton}

